\title{
SOCIALIZAÇÃO DOS PROFESSORES NO ESPAÇO ESCOLAR: (RE)CONSTRUÇÃO DE SUAS AÇÕES E IDENTIDADE PROFISSIONAL
}

Márcio André Emídio, Helena Faria de Barros

Programa de Mestrado em Educação. Universidade do Oeste Paulista - UNOESTE. E-mail: marcioandreemidio@hotmail.com

\section{RESUMO}

O presente estudo refere-se a uma pesquisa qualitativa (Estudo de Caso), ligado ao Programa de Mestrado em Educação da Universidade do Oeste Paulista de Presidente Prudente-SP na linha de pesquisa - Formação e Prática Pedagógica do Profissional Docente, que teve como objetivo investigar a socialização do professor no espaço escolar para compreender como adquirem, modificam, reconstroem conhecimentos, habilidades, convicções e atitudes próprias da profissão docente e da identidade profissional, no âmbito do exercício profissional. Para o estudo foi utilizada a Pesquisa Qualitativa - Estudo de Caso. O questionário, a entrevista, a observação e o grupo focal foram utilizados como procedimentos de coleta de dados $E$ para análise a "análise de conteúdo" indicada por Laurence Bardin e Maria Laura Franco. O Estudo teve como resultado a importância de se considerar o espaço escolar como um aspecto relevante para a socialização profissional e a confirmação de que a socialização e a constituição das identidades estão intrinsecamente relacionadas, pelo sentimento de pertença ao grupo, no qual o sujeito começa a pensar com os outros, assumindo pessoalmente as atitudes, as linguagens, a trajetória e o projeto do grupo. A socialização do professor no espaço escolar realmente influencia no processo de construção e reconhecimento da identidade profissional e da prática docente.

Palavras-chave: Formação Docente; Identidade Profissional; Socialização.

\section{INTRODUÇÃO E OBJETIVO}

Socialização profissional, no contexto desta pesquisa, significa o processo através do qual as pessoas constroem valores, atitudes, conhecimentos e habilidades que lhes permitem e justificam ser e estar em uma determinada profissão ou grupo profissional. É um processo de concretização dos ideais profissionais. Poderíamos arriscar a dizer que, sob um aspecto mais objetivo, a socialização profissional constitui-se no processo de traduzir em práticas profissionais os conhecimentos inerentes à profissão. E, sob o aspecto subjetivo, constitui-se na efetiva identificação e adesão à profissão.

Focalizando o conceito de socialização, desde Dürkheim e dos antropólogos clássicos, como Linton, Kardiner, R. Benedict e M. Mead, até Piaget e nosso contemporâneo P. Bourdieu, com seu conceito de habitus, Claude Dubar torna clara a relação desse conceito, de socialização, com o de construção da identidade. A partir daí ele refina o trabalho de análise teórica, para demonstrar o próprio processo de construção da identidade como fruto da 
superação de uma suposta bipolaridade entre forças individuais e coletivas, bastante centrada na socialização profissional. Segundo Dubar (2005, p. 256) “a socialização profissional consiste, para os indivíduos, em construir sua identidade social e profissional, através do jogo das transações biográficas e relacionais".

Ainda em seus estudos, afirma que a vivência da profissão e o partilhamento de experiências possibilitam ao professor tanto o re-ordenamento de suas ações, quanto o redimensionamento do ser professor de profissão. Essa reflexão nos leva a concordarmos, com Nóvoa (1999, p. 16) ao afirmar que "[...] a identidade é um espaço de construção de maneiras de ser e de estar na profissão [...]". Ou seja, é a partir dos percursos vivenciados na atuação pessoal e profissional, que a identidade profissional é construída, descoberta e compartilhada com os seus pares e com a instituição em que atua. É nesse espaço que vão aparecer as dimensões da formação da identidade e da socialização profissional, ligando-se estreitamente aos aspectos da formação pessoal e da formação acadêmica, ambas concorrendo para a prática pedagógica do professor.

Nesta perspectiva, é necessário apontarmos a relevância social e acadêmica do presente estudo na atual discussão acerca da profissão docente no cenário das pesquisas em educação, contemplando, principalmente, questões referentes à formação, aos saberes e à identidade docente como importantes indicadores nas análises acerca da realidade do ensino escolar nos diferentes níveis de escolarização. Neste entorno, muitos estudos referem-se à necessidade de definição sobre quem é o profissional professor, como ele se vê, onde deve ser formado, como deve ser formado e quais competências e saberes devem permear a relação teoria/prática na formação e atividade docente.

É nesse sentido que Monteiro (2010, p. 49) advoga que a formação profissional, enquanto dimensão da profissionalização, "é um processo tanto de especialização como de socialização", já que não envolve apenas a aprendizagem de conceitos e capacidades, mas também a apropriação de valores e atitudes, "através do que o candidato ao exercício da profissão aprende uma postura profissional".

Mais do que um lugar de aquisição de técnicas e de conhecimentos a formação de professores é o momento-chave da socialização e da configuração profissional. (Nóvoa, 1999 p.18) Em relação à formação inicial, pesquisas têm demonstrado que os cursos de formação, ao desenvolverem uma matriz curricular formal com conteúdos e atividades de estágios, distanciados da realidade das escolas, numa perspectiva burocrática e cartorial que não dá conta de captar as 
contradições presentes na prática social de educar, pouco têm contribuído para gestar uma nova identidade do profissional docente. Espera-se, pois, que mobilizemos os conhecimentos da teoria da educação, socialização e prática reflexiva docente, necessários à compreensão do ensino como realidade social e, que desenvolvamos nos docentes, a capacidade de investigar a própria atividade para, a partir dela, constituírem e transformarem os seus saberes-fazeres docentes, num processo contínuo de reconstrução de suas identidades como professores, talvez não permitindo a interferência dos interesses neoliberais na definição das políticas educacionais provocarem crise de identidade, o que comprometeria e quem sabe, impediria que esses profissionais correspondessem às exigências contemporâneas do exercício das suas funções.

\section{Objetivo}

O presente estudo teve por objetivo geral investigar a socialização do professor no espaço escolar para compreender como adquire, modifica, reconstrói conhecimentos, habilidades, convicções e atitudes próprias da profissão docente e da identidade profissional, no âmbito do exercício profissional.

\section{METODOLOGIA}

Nesse estudo, adotamos a pesquisa qualitativa, que ocupa um reconhecido lugar entre as várias possibilidades de se estudar os fenômenos que envolvem os seres humanos e suas intrincadas relações sociais, estabelecidas em diversos ambientes e por ser uma metodologia que destaca a descrição e a indução ao estudo das percepções pessoais. Responde a questões muito particulares, ocupa-se nas Ciências Sociais, com um nível de realidade que não pode ou não deveria ser quantificado.

A modalidade de pesquisa utilizada foi o estudo de caso, "uma investigação empírica que investiga um fenômeno contemporâneo em profundidade e em seu contexto de vida real, especialmente quando os limites entre o fenômeno e o contexto não são claramente evidentes." (Yin, 2010, p. 39)

O estudo de caso permite que seja analisada uma situação na qual não se possam fazer interferências no sentido de manipular comportamentos relevantes; nesta modalidade os dados são coletados a partir de múltiplas fontes todas baseadas em relatos, documentos ou observações. 


\section{Procedimento de Coleta de Dados}

Para a coleta de dados foi utilizados diversos procedimentos organizados em 5 (cinco) momentos:

10 momento: a pesquisa foi apresentada a todos os professores e gestores em aula de trabalho pedagógico coletivo (ATPC), e logo em seguida feito um sorteio para a seleção dos 20 professores/participantes da pesquisa.

20 momento: uso do questionário de respostas abertas.

3 momento: uso da entrevista parcialmente estruturada.

40 momento: uso da observação sistemática.

5o momento: Grupo Focal.

\section{Procedimentos de Análise de Dados}

Para análise de dados tomamos como base Laurence Bardin. A análise de dados foi organizada em 3 (três) momentos:

1 momento: a pré-análise.

2 momento: a exploração do material coletado.

3o momento: o tratamento dos resultados, a inferência e a interpretação.

Protocolo de aprovação - CCPQ - no 1503

\section{RESULTADOS}

Esse contexto, permeado de sistemas e mundos vividos, fez perceber a relevância dessa construção de conhecimento nesse espaço tão particular, a Escola, e nele fazer a leitura crítica do movimento dos sujeitos, percebendo os significados, as características, as representações e as rotinas presentes nas ações e práticas dos professores.

Este estudo no espaço escolar imprimiu a complexidade de múltiplas direções, contribuindo para uma riqueza de dados que proporcionaram diferentes perspectivas de análises relativas à construção da identidade e da ação dos sujeitos e à dialética do espaço escolar. 


\section{DISCUSSÃO}

\section{Percepção e caracterização dos momentos de socialização dos professores no}

Percebe-se a socialização dentro do espaço escolar ao notar a interação entre os membros do grupo com seus valores, suas crenças, sua cultura, mas que vão sendo alteradas ou não a partir de experiências vividas pelos sujeitos. Podemos afirmar que o professor partilha de uma cultura docente com a qual entra em interação constantemente com os iguais, com os gestores, alunos e mesmo com outros elementos da escola e que é constituída de valores, de conflitos e tensões.

Os momentos de socialização são poucos, mas bem utilizados: os ATPCs, horários de intervalo, caminho até as salas de aula, durante projeto pedagógico quando unem as salas de aula e encontros no final dos bimestres promovidos pela escola. Em destaque, afirmações dos participantes:

"Sempre que possível troco ideias com os professores e com a coordenadora que trabalha comigo."

“Durante o intervalo entre um gole de café e outro ou entre um oi e tchau na saída da

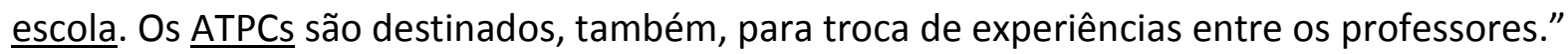

“Aprendi com a vivência em sala de aula, observando o que funciona bem, o que deveria mudar. Alguns cursos ajudaram a perceber novas estratégias, mas que nem tudo pode ser aplicado."

Entretanto a forma com a qual eles (participantes) se relacionam vai depender das disposições que foram sendo adquiridas por ele no decorrer de sua trajetória.

“A escola como espaço de socialização tem como função social sistematizar e disseminar os conhecimentos historicamente elaborados e compartilhados na comunidade que está inserida. As interações sociais que se desenvolvem neste espaço formativo, serve para ajudar os professores a se compreender e compreenderem as pessoas a sua volta."

\section{Caracterização da identidade profissional dos professores da escola}

Nota-se através da análise dos dados colhidos as características da identidade profissional dos professores da escola, e que vão de encontro aos conceitos de Nóvoa (1995), quando diz que os professores não devem ser intelectuais, mas têm de possuir um bom acervo de conhecimento; não são notáveis locais, mas têm uma influência importante nas comunidades; 
devem manter relações com todos os grupos sociais, mas devem evitar toda ostentação; não exercem o seu trabalho com independência, mas é útil que usufruam de alguma autonomia:

"Sempre acolhi tudo em minha formação: licenciatura, cursos, trabalho, colegas, escola... Sempre me envolvi, participei das tarefas do sistema. Utilizei as ferramentas e reformulei de acordo com a minha bagagem, isto é, estabeleci meu próprio balanço para poder administrar minha própria formação."

"O que eu sou hoje devo a graduação, aos cursos que participei, as trocas de experiências. E o mérito maior dou a mim mesma, pois estudei, me esforcei e ainda continuo estudando para aprimorar as minhas aulas."

“O que sei hoje, aprendi na graduação, na prática docente e no aprimoramento pessoal (estudo e cursos)."

“Aprender a aprender é uma constante na vida do professor. Aprendo a todo instante lendo muito, fazendo cursos, o professor não pode parar, o aluno exige, o tempo se transforma e o conhecimento é quem nos tira da apatia."

Tal caracterização tem indicativos sociais, econômicos, culturais e políticos que são marcados no transcorrer da história e tem interferido, e, por vezes, inviabilizado uma percepção clara da identidade profissional. Isto foi verificado quando perguntamos aos professores o que é ser professor, pois a configuração da identidade do professor está ancorada no trabalho que realiza, nas condições de trabalho, na remuneração e na importância que lhe é atribuída como profissional.

"Ser professor é mediar o conhecimento para o aluno. Fazê-lo compreender as diversas formas de leitura."

"É contribuir para o aprendizado do aluno."

"Ser professor é uma escolha, um projeto de vida e amor. Envolver o aluno na aprendizagem, fazê-lo reflexivo, crítico, responsável. É enfim fazer a diferença em sua vida."

“Nos dias de hoje ser professor é uma missão que envolve muitos deveres que vão além do aprendizado, tendo a função de não só ensinar o conteúdo, e sim trabalhar valores, limites, disciplina e ajudá-los a trabalhar a formação do psicológico, pois a maioria vem desorientado no âmbito familiar. Além de mestre, exercemos a função em alguns casos de pais, psicólogos, amigos e 'médicos da alma'." 
"Ser professor é ser comprometido com a sua profissão e com o seu público humano. Ser professor é gostar da sua profissão, mas há os que, infelizmente, não gostam. Esses são sofredores e não professores."

\section{CONCLUSÃO}

Sim, a socialização e a constituição das identidades estão intrinsecamente relacionadas, pelo sentimento de pertença ao grupo, no qual o sujeito começa a pensar com os outros, assumindo pessoalmente as atitudes, as linguagens, a trajetória e o projeto do grupo. Nesse sentido, entende-se que a teoria fornece pistas e chaves de leitura, mas o que o adulto retém está ligado a sua experiência.

Para isso, é necessário tanto reconstruir os processos de formação e de construção social que nos levaram a sustentar determinadas ideias, quanto estudar as contradições e as estruturas sociais e institucionais que condicionam a prática educativa, por isso não há dúvidas de que a socialização, o trabalho, a prática, nas diferentes escolas, vai ensinando, vai completando a formação do professor, pelo auxílio e influência de outros colegas, mas também pela própria seleção que o exercício individual da docência vai fazendo.

Tais constatações conduz a importância de se considerar o espaço escolar como um aspecto relevante para a socialização profissional. Mas infelizmente, o desenvolvimento de práticas no espaço escolar que facilitem a (re)construção do professor e, mais amplamente, a constituição de políticas para a socialização profissional, ainda é uma questão pouco colocada em nossa literatura e prática educacional.

\section{REFERÊNCIAS}

CONTRERAS, José. A Autonomia de professores. 2a ed. São Paulo: Cortez Editora, 2012.

DUBAR, Claude. A Socialização: Construção das Identidades Sociais e Profissionais. São Paulo: Martins Fontes, 2005.

MONTEIRO, A. R. Auto-regulação Profissional na Educação. Lisboa: CIE/FC, 2010.

NÓVOA, António. As organizações escolares em análise. 2. ed. Lisboa: Dom Quixote, 1995.

NÓVOA, António. Profissão Professor. 2a ed. Porto: Porto Editora, 1999.

SHÖN, Donald A. Educando o Profissional Reflexivo: um novo design para o ensino e a aprendizagem. Porto Alegre: Artmed, 2000. 
SHÖN, Donald A. La formación de profissionales reflexivos. Barcelona: Paidós, 1992.

YIN, Robert K. Estudo de Caso: Planejamento e Métodos. 4a ed. Porto Alegre: Bookman, 2010.

ZEICHNER, Kenneth M. A Formação Reflexiva dos Professores: ideias e práticas. Lisboa: Educa, 1993.

ZEICHNER, Kenneth M. Tendências da Pesquisa sobre Formação de Professores nos Estados Unidos. Revista Brasileira de Educação. São Paulo, n. 09, 1998. 